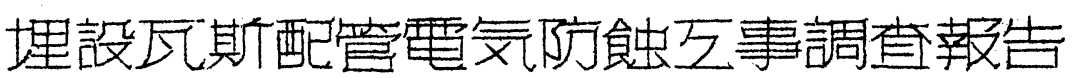

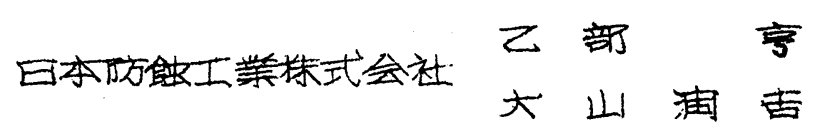

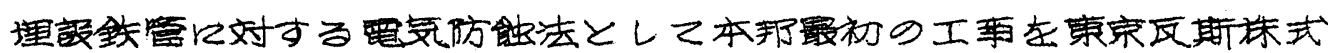

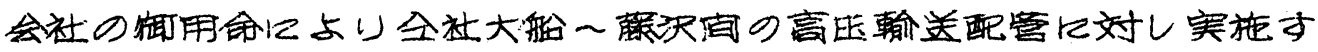

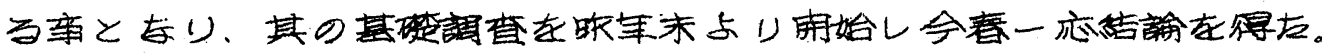

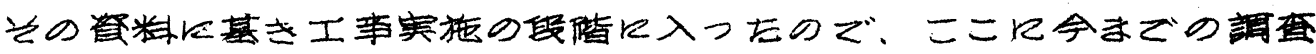

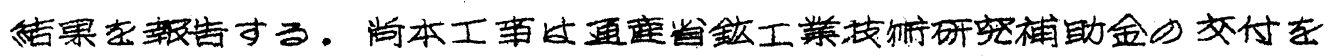

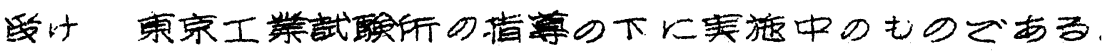

\title{
(ノ) 理银铁管の状涴
}

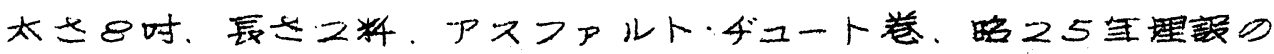

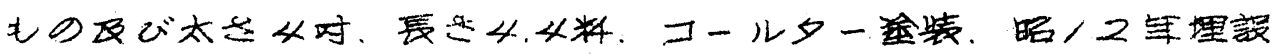
カものである。

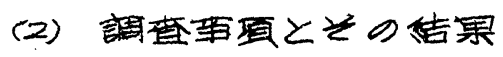

(イ) 配它の土境に对する位测定

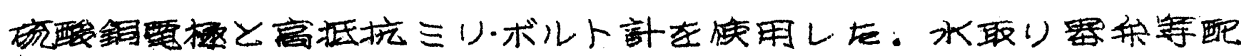

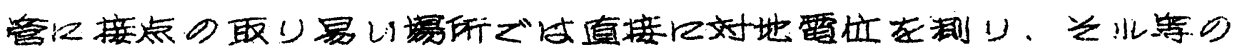

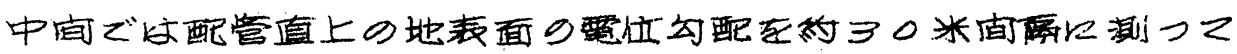

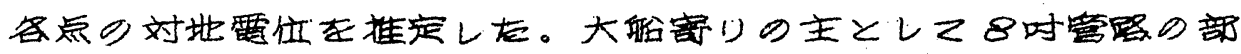

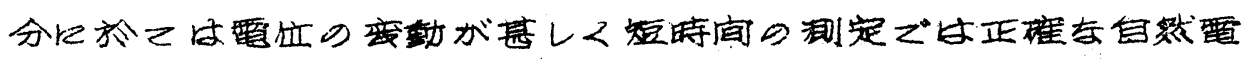
位在知る茟は四淮であつた。

(口) 管內流の則定

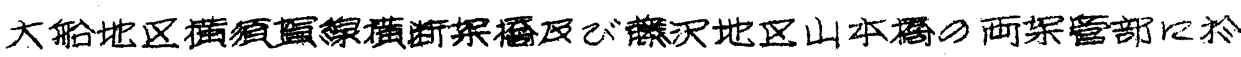

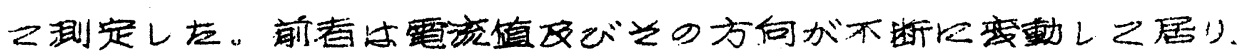

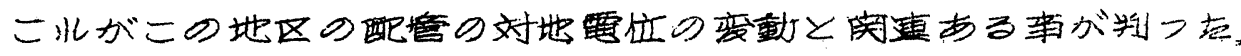

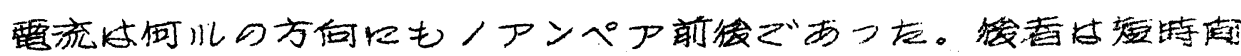

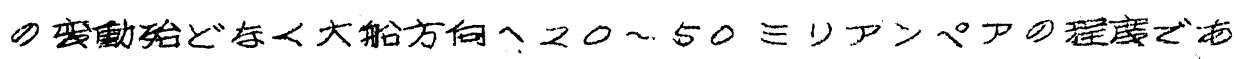


$>$ 正。

\section{(い)士壤比抵坑の测定}

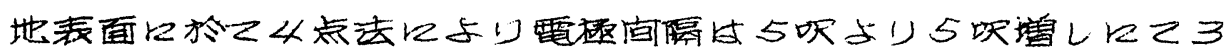
○吹きで即定しを。測定地点は管路治いに代表的地点25ケ所 を遥した。

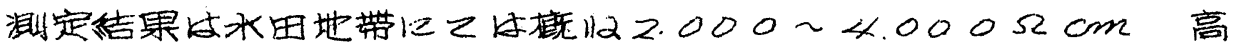

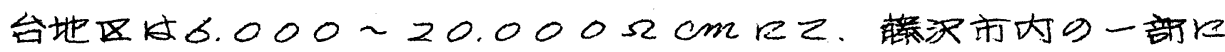

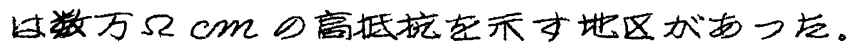

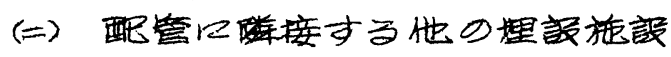

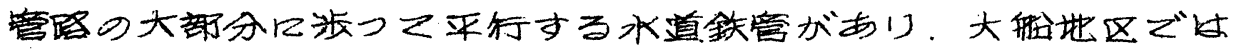

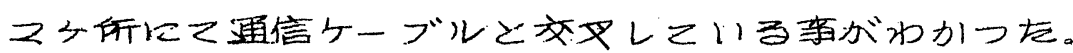

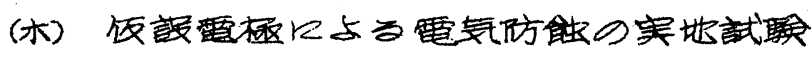

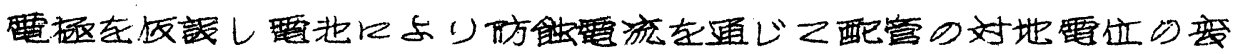

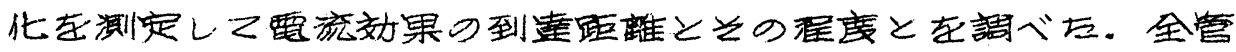

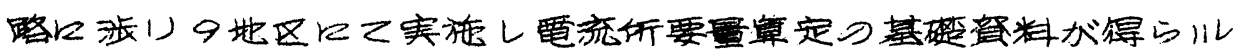

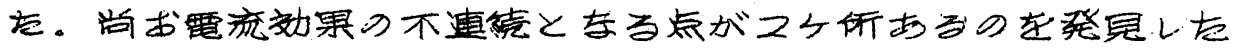

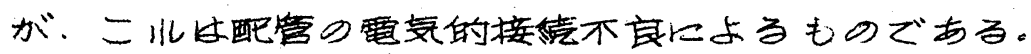

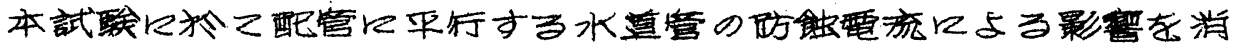

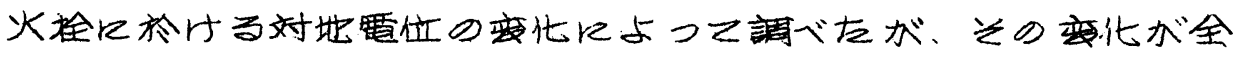

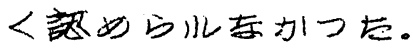

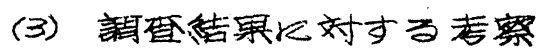

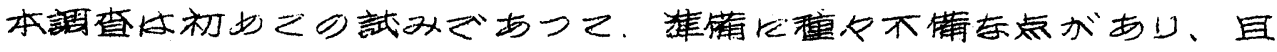

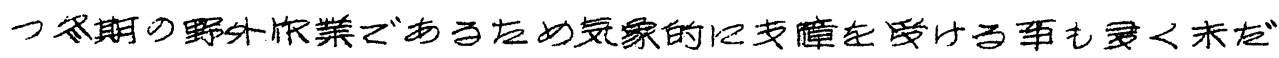

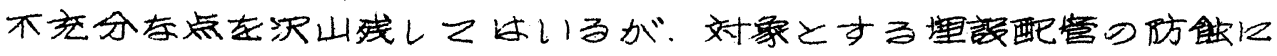

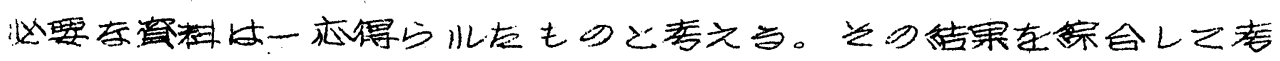
繁す川ば大要次の通りである。

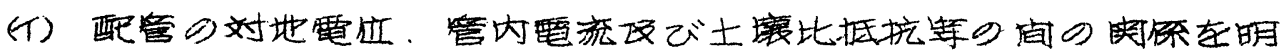

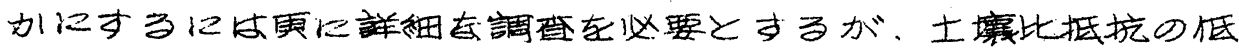

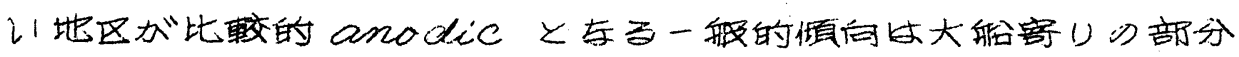
浪功た。 


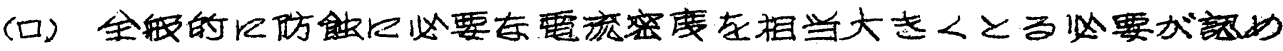

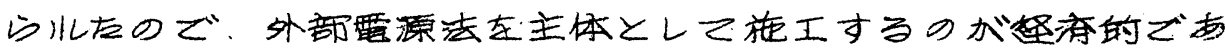
るとえらルる。

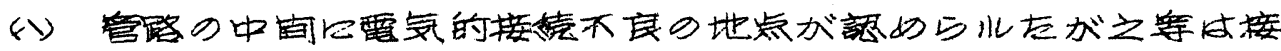

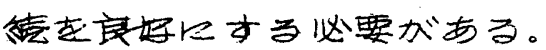

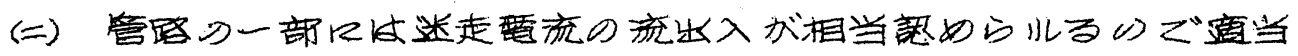

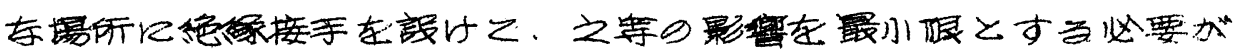
古。

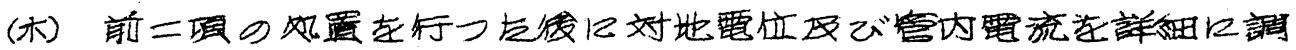

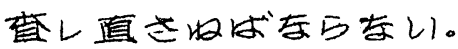

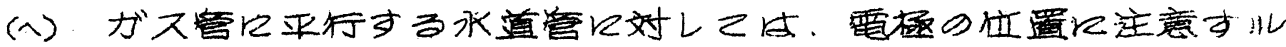

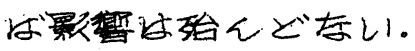

尌

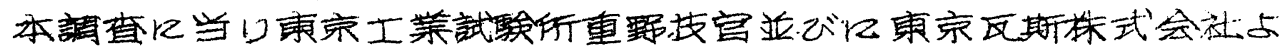

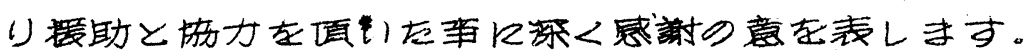

\section{珪素鉄の耐酸性に及!゙す銅の影響}

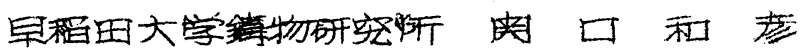

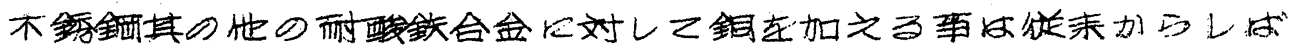

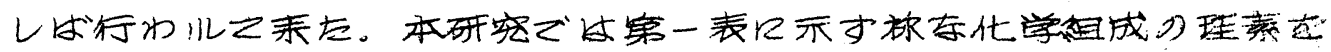

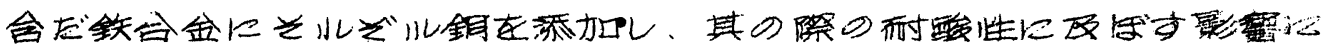
フレて研在行った。

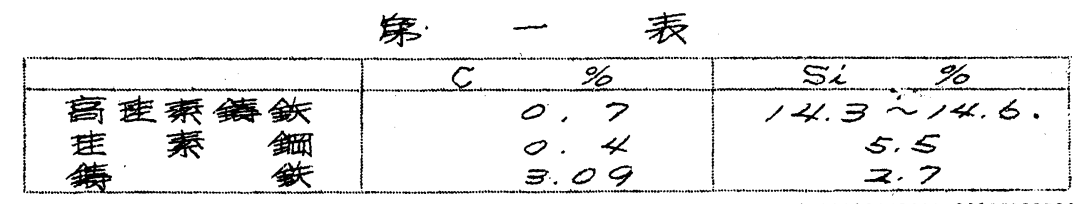

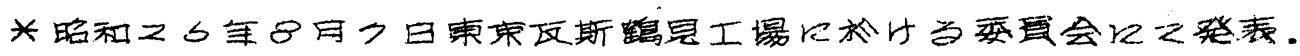

